\title{
Delayed Esophageal Perforation after Cervical Spine Plating
}

\author{
Seong Jung $\mathrm{Kim}^{1}$, Chang II Ju${ }^{2}$, Dong Min $\mathrm{Kim}^{3}$, Seok Won $\mathrm{Kim}^{2}$ \\ Departments of Emergency Medicine ${ }^{1}$, Neurosurgery, Internal Medicine ${ }^{3}$, Chosun University College of Medicine, Gwangju, Korea
}

Although anterior approaches to the cervical spine are popular and safe, they cause some of complications. Esophageal perforation after anterior spinal fusion is a rare but potentially life-threatening complication. We present a rare case of delayed esophageal perforation caused by a cervical screw placed via the anterior approach. A 43-year-old man, who had undergone surgery for complete cord injury at another orthopedic department 8 years previously, was admitted to our institute due to painful neck swelling and dysphagia. Radiological studies revealed a protruding screw and esophageal perforation. The perforation was found during surgery and was successfully repaired. This case emphasizes the need for careful long-term follow-up to check for delayed esophageal perforation in patients that have undergone anterior cervical spine plating.

Key Words: Anterior cervical surgery $\cdot$ Esophageal perforation

\section{INTRODUCTION}

Anterior cervical spine fusion and stabilization is a well established procedure for cervical myelopathy, radiculopathy, neoplasms, and cervical trauma ${ }^{2}$. Although injuries to the pharynx and esophagus are known complications of anterior cervical spine surgery, delayed pharyngeal or esophageal perforation is rare ${ }^{7,9,10)}$. Here, we describe a rare but potentially life-threatening complication after anterior cervical spine fusion and plating. The authors highlight this issue by presenting this case, which had no associated morbidity, and include a review of the relevant literature.

\section{CASE REPORT}

A 43-year-old man was admitted to our institute with a 3-month history of dysphagia and neck pain with swelling. He was paraplegic due to a C6-7 fracture and dislocation and has been operated on 8 years previously. Initial surgical treat-

\footnotetext{
- Received: May 6, 2013 - Revised: July 12, 2013

- Accepted: July 16, 2013

Corresponding Author: Seok Won Kim, MD

Department of Neurosurgery, School of Medicine, Chosun University, 588,

Seosuk-dong, Dong-gu, Gwangju 501-717, Korea

Tel: +82-62-220-3126, Fax: +82-62-227-4575

E-mail:ns64902@hanmail.net/chosunns@chosun.ac.kr
}

This study was supported by research funds from chosun university grant 2007 ment included anterior corpectomy of C7 and anterior iliac crest graft placement using a plate and screws. Hematological studies including erythrocyte sedimentation rate (ESR) and C-reactive protein (CRP) were normal. A simple lateral radiograph and a computed tomography scan showed partial anterior migration of the lower screw. A hydro-soluble contrast swallow image confirmed esophageal perforation (Fig. 1). The protruding screw was observed during emergent esophagoscopy (Fig. 2). Surgery was scheduled for removal of offending screw. The loose screw was removed and esophageal perforation was found during surgery and repaired directly by a cardiovascular team (Fig. 3). The patient was fed using a nasogastric tube for 3 weeks and subsequently oral feeding was gradually resumed. Further progress was favorable, and a contrast study performed at 3 weeks postoperatively showed no evidence of fistula.
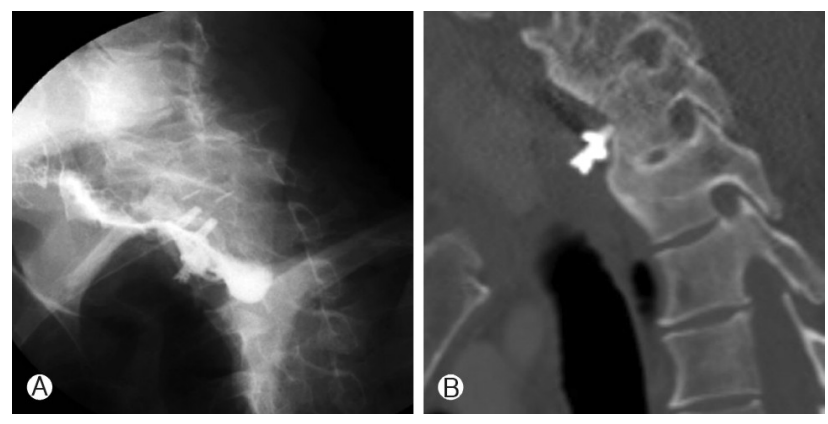

Fig. 1. Radiological studies of the patient. (A) Contrast study shows anterior displacement of the cervical screw and the fistulous tract at the bottom (arrow). (B) Sagittal computed tomograph scan showing anterior displacement of the cervical screw. 


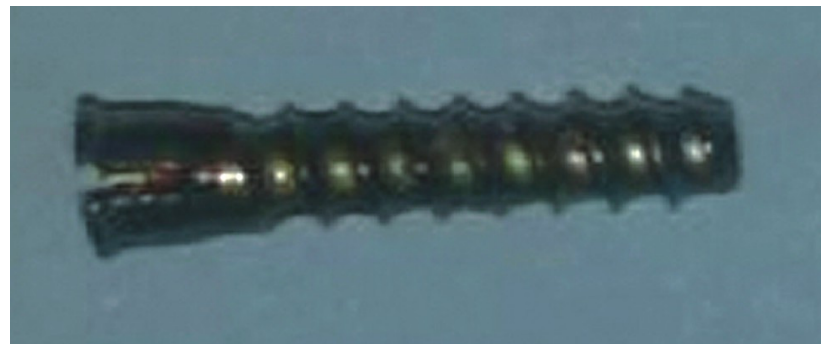

Fig. 3. Photograph of the removed offending screw.

\section{DISCUSSION}

Anterior cervical fusion and plate fixation is an effective procedure for the treatment of cervical myelopathy or radiculopathy and cervical spine trauma. Plating has been reported to achieve a fusion rate of up $98 \%$, and to result in early mobilization, reduced graft-related complications (especially for multilevel fusion), and to avoid late deterioration of the cervical spine alignment obtained at surgery ${ }^{1,4)}$. The complication rate after anterior cervical plating is generally low and decreases with surgeon's experience. According to Zeidmann ${ }^{14)}$, the overall complication rate associated with anterior cervical spinal fusion is approximately 5\%, and pharyngo-esophageal perforation is uncommon, but nevertheless of the utmost importance because of the possibility of graft infection leading to osteomyelitis, mediastinitis, sepsis, and death ${ }^{6}$. Surgical causes of esophageal perforation may be subdivided into acute or delayed. Acute injury can be caused iatrogenically during surgical approach due to inappropriate placement or dislodgement of sharp-toothed retractor blades in the esophagus. Retraction is particularly dangerous when a nasogastric tube is positioned because the wall of the hypopharynx or esophagus may be "trapped" by a high-pressure claw between the retractor and the tube, causing ischemic injury and secondary perforation $^{8)}$. Delayed esophageal injuries are due to chronic compression or contact and subsequent necrosis, abscess formation, and perforation due to graft dislodgement or screw migration with or without plate failure ${ }^{4,7}$. Screw dislodgement often follows a benign course and is completely asymptomatic, due to the small diameters of the screws used and slow migration from the external to the internal mucosa, which permits spontaneous tissue repair of the defect caused. Migrated screws can be eliminated through the gastrointestinal tract ${ }^{3,5}$. Repetitive friction between the retropharyngo-esophageal wall and the plating system (normally positioned with adhesion), traction-type pseudodiverticulum, and perforation are other causes of delayed injury ${ }^{11)}$. The complications of esophageal perforation range from asymptomatic with local in-

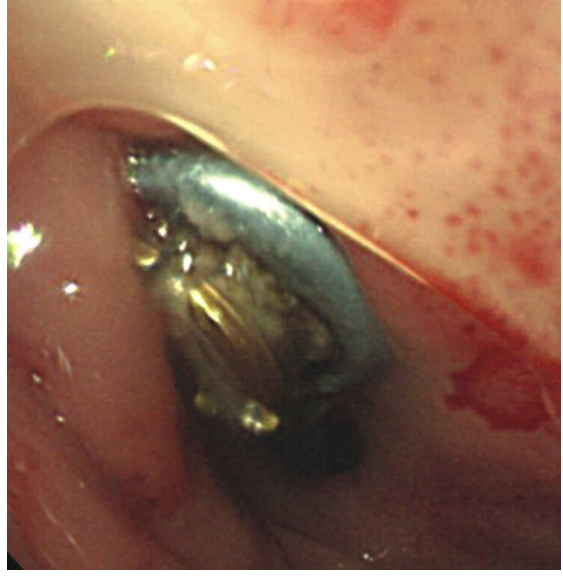

Fig. 2. The screw was observed during emergent esophagoscopy.

fection to mediastinitis and death. The clinical course depends on the etiology, location, and timing of the perforation. Asymptomatic perforation has as well been reported as incidental oral extrusion of screw even years after anterior cervical spine stabilization ${ }^{5)}$. Patients generally present with swallowing difficulty, regional swelling, neck pain, dysphagia, weight loss, dysphonia, subcutaneous emphysema, and fever; our patient presented with dysphagia and neck pain with regional swelling ${ }^{12,13)}$. Conservative treatment may be preferred for small, contained defects of less than $1 \mathrm{~cm}$, and consists of the elimination of oral feeding, tube feeding to restore fluid and nutritional balance, and intravenous antibiotics. Some cases need surgical repair, such as, perforation closure with a primary suture or sternocleidomastoid or pectoralis major flap repair ${ }^{13)}$. We operated on our patient to remove the offending screw due to evident fistula confirmed by esophagography and esophagoscopy. Direct repair was effective in achieving a successful perforation repair of the esophageal perforation with an early return to oral feeding.

\section{CONCLUSION}

We report a rare case of delayed esophageal perforation caused by screw displacement after anterior cervical spine plating. Careful periodic follow-up is necessary, and when encountered, early surgical closure following removal of the offending screw is mandatory.

\section{REFERENCES}

1. Bose B: Anterior cervical fusion using caspar plating: analysis of results and review of the literature. Surg Neurol 49:25-31, 1998 
2. Caspar W, Barbier DD, Klara PM: Anterior cervical fusion and caspar plate stabilization for cervical trauma. Neurosurgery 25: 491-502, 1989

3. Geyer TE, Foy MA: Oral extrusion of a screw after anterior cervical spine plating. Spine 26:1814-1816, 2001

4. Konstantakos AK, Termes RT: Delayed esophageal perforation: a complication of anterior cervical spine fixation. Ann Thorac Surg 80:349, 2005

5. Lee JS, Kang DH, Hwang SH, Han JW: Oral extrusion of screw after anterior cervical interbody Fusion. J Korean Neurosurg Soc 44:259-261, 2008

6. Navarro R, Javahery R, Eismont F, Arnold DJ, Bhatia NN, Vannis, et al: The role of the sternocleidomastoid muscle flap for esophageal fistula repair in anterior cervical spine surgery. Spine 30: 617-622, 2005

7. Newhouse KE, Lindsey RW, Clack CR, Lieponis J, Murphy J: Oesophageal perforation following anterior cervical spine injury. Spine 14:1051-1053, 1989

8. Orlando ER, Caroli E, Ferrante L: Management of the cervical esophagus and hypopharynx perforations complicating anterior cervical spine surgery. Spine 28(15):290-295, 2003

9. Ryu Jl, Cheong JH, Bak KH, Kim CH, Kim JM: Delayed esophageal perforation after cervical osteosynthesis. Korean J Spine 2:80-83, 2005

10. Sharma RR, Sethu AU, Lad SD, Turel KE, Pawar SJ: Pharyngeal perforation and spontaneous extrusion of the cervical graft with its fixation device: a late complication of $\mathrm{C} 2-\mathrm{C} 3$ fusion via anterior approach. J Clin Neurosci 8:464-468, 2001

11. Witwer B, Resnick DK: Delayed esophageal injury without instrumentation failure: complication of anterior cervical instrumentation. J Spinal Disord Tech 16:519-523, 2003

12. Wong TD, Fehlings MG, Massicotte ME: Anterior cervical screw extrusion leading to acute upper airway obstruction. Spine 30: 683-686, 2005

13. Yee GKH, Terry AF: Esophageal penetration by an anterior cervical fixation device. Spine 18:522-527, 1993

14. Zeidmann SM, Ducker TB, Raycroft J: Trends and complications in cervical spine surgery: 1989-1993. J Spinal Disord 10: 523-526, 1997 